DOI: https://doi.org/10.25146/2587-7844-2019-8-4-27

\title{
УДК 812
}

\section{РЕЧЕВОЙ ЖАНР ИНТЕРНЕТ-ТРАВЕЛОГА: ТЕМАТИЧЕСКИЕ ОСОБЕННОСТИ}

\section{Е.В. Богучарская (Красноярск, Россия)}

\section{Аннотация}

Травелог - популярный речевой жанр в интернет-среде, границы которого еще не установлены. В статье рассматриваются тематические особенности интернет-травелога, являющиеся одним из его жанрообразующих признаков. Материалом для исследования стали тексты непрофессиональных авторов, опубликованные на специализированных туристических сайтах и на сервисе онлайн-дневника «Живой журнал». На уровне содержания интернет-травелог как речевой жанр характеризуется широким кругом рассматриваемых тем и разнообразием их выражения. Определение комбинации описываемых тем напрямую зависит от образа автора, интересующегося разными аспектами путешествия.

Ключевые слова: речевой жанр, анкета речевого жанра, травелог, интернет-травелог, тема, пейзажный, городской, философский, мужской, женский травелоги.

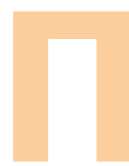

остановка проблемы. Сегодня травелог является одним из наиболее популярных речевых жанров, нашедших развитие в Интернете - одной из глобальных сфер коммуникации; о стратификации современного коммуникативного пространства в теории речевых жанров см. [Гиндин, 2015; Осетрова, 2012].

В лингвистике, как и в других науках, существует терминологическая проблема определения «травелога». В статье «Интернет-травелог: к вопросу о лингвистической интерпретации» Е.Г. Басалаева и О.А. Ружа рассматривают травелог как метажанр интернет-дискурса, создателем которого может стать любой человек, поэтому на первый план выходит не индивидуальность автора и его стиль, а интенции, эмоции и впечатления [Басалаева, Ружа, 2011, с. 561]. Т.Ю. Редькина рассматривает травелог как трэвел-медиатекст, который представляет страну через совокупность признаков (географическое положение, природный мир, народ, язык, нравы, история и культура, государственное устройство, общественнополитическая ситуация) с целью информирования (факультативными являются интенции развлечения и убеждения), появляется этот текст в результате путешествия как социокультурное действие [Редькина, 2014, с. 152].

Содержание жанра в интернет-травелоге всегда связано с описанием путешествия, именно оно является главным событием в тексте. Путешествие предполагает выход за границы обыденного и повседневного, открытие и познание нового, незнакомого пространства, преодоление своего инстинкта самосохранения и привычки к оседлому образу жизни. По мнению О. Никифорова, «травелог - это обращение к некоторой фактографии земли, путешествие сквозь землю, извест- 
ную или неизвестную, но всегда заново, индивидуально переживаемую, в перспективе - обретение некоей истины, которая может стать истиной для многих» [Кириллов, 2015, с. 4]. Описание путешествия может включать разные аспекты, интересные конкретному автору, поэтому в данном жанре содержание напрямую зависит от образа автора, его интересов и особенностей восприятия. Тем не менее можно создать типологию интернет-травелогов на основе видовой принадлежности описываемых объектов и тематического содержания описания.

Во-первых, в самом широком смысле травелог может быть посвящен изучению природного или городского пространства, что определяет выбор объектов для описания. Например, в текстах про посещение заповедников, прохождение экотроп, выезды за город или специальные экспедиции обязательно будут присутствовать экологические мотивы, рассуждения о величии природы, единении с ней человека, возвращении к истокам, описание красоты флоры и фауны, увиденных по маршруту, причем всегда, даже несмотря на плохую погоду или потерю ориентации на местности, отзывы будут положительными, характеризующими рефлексивную, эстетическую и релаксирующую функции путешествия на природу. В качестве примера можно привести следующие травелоги с говорящими названиями: «Удивительный парк секвой» (Варламов, 2016), «Как насладиться золотом Черных гор» (Доля, 2017), «Рассвет в волшебном лесу» (Странник, 2016) и др.

Во-вторых, интернет-травелог может быть посвящен описанию своего пространства или чужого. Для русского человека родной будет являться территория России с традиционной культурой и населением, говорящем на русском языке. Путешествия по России обычно связаны с посещением двух столиц государства, Москвы и Санкт-Петербурга, или же близлежащих территорий. В изучении своей малой родины можно выделить два основных мотива: патриотизм или отсутствие нужного для дальнего путешествия уровня доходов. Приведем названия некоторых травелогов о России: «Звенигород. В ожидании весны» (Dzeso, 2016), «Через всю Россию на Байкал» (Рубченкова, 2015), «Побег в Воронеж» (Shish_ka, 2016) и др. Чужое пространство, то есть другие страны, привлекают в первую очередь своей экзотикой, бегством от повседневности, открытием нового и преодолением себя. Для многих туристов именно поездка за границу становится значимым событием, достойным описания в интернет-травелоге. Примерами могут служить следующие названия: «Самый „невьетнамский” город Вьетнама Далат» (Екатерина, 2016), «Под небом Парижа» (Екатерина, 2015), «Как живет американская глубинка» (Беленький, 2016).

В-третьих, в интернет-травелогах описывается либо все путешествие целиком, либо конкретное событие, ограниченное временными рамками внутри путешествия. В первом случае обычно получается травелог обзорного типа, передающий самые общие впечатление, например атмосферу незнакомой страны или города: «Рязань как стиль жизни» (Гордеева, 2017), «Бросить все и уехать в Питер» (Гордеева, 2016), «Для меня Сан-Франциско - сугубо американский город» (Познер, 2016). 
Цель статьи - рассмотреть тематические особенности интернет-травелога, являющиеся одним из его жанрообразующих признаков.

Meтоды исследования: общенаучные (метод описания, анализа) и собственно лингвистические (метод контекстного анализа, метод лингвистической интерпретации, метод пофакторного анализа речевого жанра).

Результаты исследования. Обратимся к тематическому содержанию травелогов. Круг тем, поднимаемых в интернет-травелогах, достаточно широк. Их можно объединить в следующие группы: научные сведения о посещаемом месте (лингвистика, история, география, биология), описание природы (состояние, флора и фауна, экология), информация об устройстве исследуемого общества (данные о народной культуре, искусстве, религии, экономике, политике, повседневной жизни), описание быта путешественника (еда и напитки, покупки, транспорт и дороги, погода, расходы), сравнительный анализ (параллели с другими путешествиями, посещенными объектами, местом жительства, произведениями искусства), философские рассуждения о жизни и смерти, природе, пространстве и времени, изменении человека в путешествии. Рассмотрим указанные темы подробнее.

Научные сведения в интернет-травелоге встречаются очень часто, благодаря им читатель может сэкономить время при подготовке к путешествию или расширить кругозор. Чаще всего обращаются к лингвистическим данным, особенно из области этимологии: Название подворья происходит от слова «Крутищзы». Так в древности называли все возвышенности, лежащчие на левом берегу Москвьреки, начиная от реки Яузы вплоть до урочищза Симоново (Shish_ka, 2015). Pacсматриваются также особенности произношения: Бат (в течение пути мне скрупулезно и с самым серьезным видом объясняли, что мое задумчивое «ээээээ... Бат» - это ванна, а город - лаконичное, четкое и уверенное "Bath» на выдохе (ну прямо как Апчхи, только начинается с Б) (Буянова, 2016). Авторы интересуются и вопросами словообразования, особенно связанного с наименованием жителей посещаемых мест: Как лучше сказать - барнаулочки или барнаулицьь? (Доля, 2013). Нередко проводится сравнение русского языка с другими славянскими на бытовом уровне, к примеру, при помощи вывесок: «Мужская $u$ женская одежда» на украинском языке внешне похожа на «человеческую и женскую» (Доля, 2013). Авторы интернет-травелогов также приводят интересные наблюдения о городских топонимах, обращая внимание, например, на необычные вывески, как в Красноярске Артемий Лебедев негативно прокомментировал вывески ларьков «Розпечать» как Новое в правописании (Лебедев, 2008).

Историческая информация в путешествии не менее важна, наряду с ней приводятся и фольклорные данные, которые всегда привлекают читателей, создают романтический ореол места (Бродя среди словно изысканно нарисованных силуэтов средневековых изерквей, замков и дворцуов, чувствуешь, как оживают на улицุах этого города страниц̧ь истории (Юлия, 2019)). Географические и биологические сведения менее распространены. 
Описание природы встречается в разных ситуациях: когда целью путешествия как раз и является природный объект вне городского доступа (заповедник, горы, каньон залив и т.д.), когда природный объект находится в пределах города, например парк, зоопарк или ботанический сад, когда наблюдения за природой происходят по дороге, во время переезда, то есть не считаются основными. В первом случае возникает пейзажный травелог: Осень раскрасила каньон в палевые извета, с вкраплением красных крон деревьев и остатков зеленого. Летом кромка каньона сиреневая от изветущуего чабреца, и это совершенно фантастическое зрелище (Лискер, 2016). Во втором случае наряду с описанием местной флоры и фауны рассматривается и наличие инфраструктуры. Так, Илья Варламов, рассказывая про парк секвой, восхищается не только невероятной красотой деревьев, но и наличием хорошо организованных мест для отдыха, трекинговых троп и специальных шаттлов (Варламов, 2016).

Самая распространенная тематическая группа - описание общества. Авторам интернет-травелогов всегда интересна культура посещаемого объекта, в частности незнакомые традиции, обычаи и обряды: Говорят, что даже сейчас есть обычай - каждый моряк, вернувшийся домой, должен бросить камень возле скальл... (Татьяна, 2018). Из описания глубоких наблюдений и возникает образ народа в глазах иностранца, как, например, следующий: Узбеки - люди кропотливого труда. В каждой семье передают из поколения секреть рукоделия, традиционные ремесла не просто живы, а продолжают развиваться... А более душевный народ ещуе нужно поискать! (Беленький, 2018). К сожалению, говоря о России, путешественники чащи упоминают недавно сформировавшиеся и далекие от культурной составляющей порядки: То есть для краснояриеев считается нормальным приехать на набережную, взять кальян, снова сесть в свою повозку и дылмть! Они прямо так и сидят среди свочх вонючих мачин, потягивают пивасик и дымят (Варламов, 2016).

В мужском травелоге авторов интересуют религиозные, экономические и политические особенности посещаемого объекта, поэтому в текстах появляется серьезный анализ истории, современного состояния и перспектив исследуемого общества. Иногда они позволяют себе оценочные суждения, нарушающие этические нормы: Верующие в религиозном экстазе по многу часов пляшут и поют молитвы, стоя на берегу моря. Море, разумеется, исполняет роль усилителя молитвы (Лебедев, 2012).

Описание произведений искусства свойственно как мужскому, так и женскому травелогу и напрямую зависит от уровня образования и культуры автора интернет-травелога. Отдельно можно выделить восприятие современного искусства, чаще всего не принимаемого и критикуемого: Ecmь в Хорне и более современное искусство. Я честно не знаю, что это может означать. Если вообще должно что-то значить (Варламов, 2019).

Важной частью любого травелога является изучение повседневной жизни незнакомого объекта, нередко оно становится целью всего текста. Интересно мо- 
жет быть абсолютно все: распорядок дня, еда, одежда, часы досуга, отношения в семье и т.д. К этой же области можно отнести и проблемы современного общества, например, чрезмерное распространение гаджетов, влияние массовой культуры, неравенство социальных групп и др. Еще больший интерес вызывает быт самих путешественников, ведь он кардинально отличается от привычного им образа жизни. В первую очередь это, конечно же, необычные еда и напитки, к примеру: Кроме того, меня впечатлили крохотные, на один укус, пирожки с мелко порубленныл копченыл салом (Буянова, 2014).

Авторы интернет-травелогов не жалеют красок при описании национальных блюд, особенно женщины. Приведем цитату из женского травелога: Нежнейшая паровая булочка с мармеладом, политая заварным кремом... Съесть в одиночку тяжело даже сладкоежке со стажем (Буянова, 2016). Женщины обычно описывают каждый прием пищи с перечислением блюд, тогда как мужчины ограничиваются только упоминанием самого факта трапезы: Утром собрали вещзички, позавтракали и, вознеся молитвы, отпльли из Марбельи (Левченко, 2017). Внимание к деталям и повседневным радостям, возможно, и делает путешественников такими счастливыми людьми: Для меня Дрезден стал буквально синонимичен cлову «wurst». Вюрст - это такие аппетитные подкопченные колбаски, которые здесь продают на каждом углу. Аромат - божественный, а вкус дарит ошущзение рая на Земле (Елизавета, 2016).

Для женщин также очень актуально описание посещения местных рынков и магазинов, в которых они покупают национальные товары, что становится особым пунктом в интернет-травелогах, так как в совокупности с красочной характеристикой разнообразных предметов автор демонстрирует свое мироощущение, близкое почти всем читательницам: Уж насколько я не любитель любых головных уборов, и то не выдержала и приобрела себе чудную шапочку из нежнейшей шерсти ягненка (Буянова, 2014). Мужчин же больше интересует описание транспорта, на котором они передвигаются во время поездки, особенно если он отличается от привычного русского: Но я предпочитаю путешествовать только за рулем. Поэтому взял в прокат вот этот автомобиль Chevrolet Nexia 3. B остальном мире такой называется Ауео (Беленький, 2018). А вот состояние дорог с одинаковым интересом описывают представители обоих полов: После этого скорость заметно падает, дорога преврашцается в «стиральную доску» и отныне до самого Лаутрабьярга проходит в пьли и небольшой тряске, забираясь местами довольно высоко (Андреева, 2018). Кроме того, общими темами будут обсуждения погоды, являющейся важным фактором для успешной прогулки и хорошего настроения (Даже плохая погода этому краю клииу: ненастный день на Скадарском озере (Беленький, 2016)), описания расходов (стоимость еды, товаров, транспорта, билетов для посещения достопримечательностей и др.). Однако среди целей жанра нет детального описания материальной стороны поездки, ведь на первый план выходит целостное восприятие посещаемого объекта, впечатления от увиденного, эмоции и мысли. 
Важным тематическим аспектом является сравнительный анализ, используемый в текстах интернет-травелогов. Путешественники используют свой опыт и сравнивают текущую поездку с предыдущими в то же самое место: $A$ я пыталась сопоставить картинку пятилетней давности с тем, что вижу сейчас, и совершенно не узнавала место - голая земля и мутная вода залива исчезли, как по мановению волшебной палочки, уступая место сказочным деревьям (Лискер, 2016). Авторы составляют свой рейтинг посещенных мест на основе общих впечатлений по шкале «понравилось - не понравилось» (Красиво, как в Бирюлево (Варламов, 2016) про один из районов Нью-Йорка), «интересно - не интересно» (да $u$ не интересный он, крупнейший город Фландрии, в сравнении с очаровательныл Гентом или сказочныл Брюгге (Беленький, 2016)).

Широко распространена практика сравнения родного и чужого пространства. Это, конечно, чаще свойственно так называемому мужскому (аналитическому) травелогу, в котором автор не просто эмоционально воспринимает обстановку, но и подробно разбирается, в чем заключаются различия. Модус высказываний может быть как положительный (Марракешские ворота - отдельная достопримечательность. Они словно резные ставни в деревнях Кировской области или русского севера (Доля, 2015)), так и отрицательный (Вообще, Шотландия похожа на Россию. Красивая природа, ужасная погода, и все пьют (Беленький, 2015)), но большая часть сравнений проходит не в пользу русской действительности. Привлечение опыта путешественника позволяет критиковать проблемы особенно иронично: Северная Корея бы позавидовала экономности новосибирских коммунальщзиков (Варламов, 2016). Сравнительный анализ используют в основном опытные путешественники, делая интернет-травелог еще интереснее для читателя и мотивируя больше путешествовать, чтобы расширять свой кругозор и объективно оценивать окружающую действительность.

Интерес представляют отсылки к произведениям разных видов искусства. К примеру, путешественники вспоминают песни, соответствующие определенному моменту (Ширь необъятная, воздух изумительный, голубое небо, изумрудные леса, так и хочется сказать, как Шахрин из Чайфа: АА, мама, ну до чего ж хорошо!» (Пушкарева, 2018)) или книги (Вспомнила про хозяйку медной горы из рассказов Бажова и больще не могла глаз отвести от этой горной владычицьь, будто спрашивая разрешения на каждый шаг на ее территории, только бы не потревожить (Ренева, 2018)).

К заключительной распространенной тематической группе можно отнести философские рассуждения, так как жанр травелога подразумевает демонстрацию путешествия через призму мировоззрения автора и его духовных изменений. В первую очередь речь идет о категориях пространства и времени, так как их восприятие не может не измениться в поездке: Таким образом, мы остались вдвоем в этом волиебном месте, время куда-то пропало, остались лишь море, солнuуе, очертания скал и тишина (Пилигрим, 2016). С категорией времени тесно связаны рассуждения о жизни и смерти. Смысл жизни нередко сводится к путеше- 
ствию как к открытию нового пространства и испытанию себя: Никогда не сидите на месте, путешествуйте, знакомьтесь, влюбляйтесь, ошибайтесь, смейтесь! Ведь только чувствуя какие-то эмоции, мы действительно живем! (Петрова, 2015). Приводятся даже инструкции, как быть счастливым: Mbl счастливы, пока имеем возможность встречать рассветы и провожать закатыл. Mы счастливы, пока рядом с нами есть люди, с которыми можно просто помолчать. Мы счастливы, пока тебя ждут. Мы счастливы, пока тебе рады (Гордеева, 2017).

Пейзажные интернет-травелоги не могут не затрагивать глобальные темы взаимодействия природы и человека. Оставаясь наедине с природой, автор рассуждает о ее величии и бесконечности, влиянии на людей: Но, наверно, самое характерное ощущуение, которое испытывает каждый в горах, - это ощуццение незначительности, быстротечности жсини маленького человечка перед постоянством и величием гор. И в то же время здесь, как нигде, хочется слиться с дивным пейзажем, стать частью этого неповторимого в своей красоте и многообразии горного мира (Пилигрим, 2013).

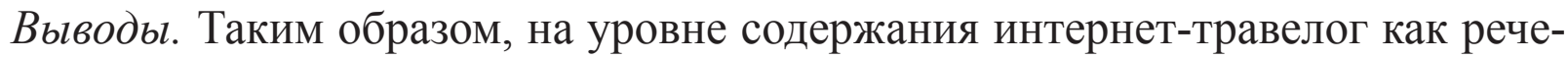
вой жанр характеризуется широким кругом рассматриваемых тем и разнообразием их выражения. Можно выделить следующие тематические группы: научные сведения из разных областей, природа, устройство и образ жизни общества, быт путешественника, сравнительный анализ, философские рассуждения. Определение комбинации описываемых тем напрямую зависит от образа автора, интересующегося разными аспектами путешествия.

\section{Список источников}

1. Андреева К. Исландия: тупиковый путь. 2018. URL: https://www.tourister.ru/world/europe/ iceland/city/keflavik/placeofinterest/30029/responses/4207 (дата обращения: 10.08.2019).

2. Беленький А. Как живет американская глубинка. 2016. URL: http://macos.livejournal. com/1392049.html (дата обращения: 10.08.2019).

3. Беленький А. Когда очень хочется в Черногорию. 2016. URL: http://macos.livejournal. com/1440163.html (дата обращения: 10.08.2019).

4. Беленький А. Старая Зеландия. 2016. URL: http://macos.livejournal.com/1443085.html (дата обращения: 10.08.2019).

5. Беленький А. Узбекистан. Зачем туда вообще ехать? 2018. URL: https://macos.livejournal. com/1739254.html (дата обращения: 10.08.2019).

6. Беленький А. Шотландия. Первые впечатления. 2015. URL: http://macos.livejournal. com/1046958.html (дата обращения: 10.08.2019).

7. Буянова А. Бавария и я: Аугсбург. 2016. URL: http://www.tourister.ru/responses/id_14456 (дата обращения: 10.08.2019).

8. Буянова Д. От Лондона радиалочкой. 2016. URL: http://www.tourister.ru/responses/id_17968 (дата обращения: 10.08.2019).

9. Буянова А. Скромное очарование Риги, или как полюбить пирожки с салом. 2014. URL: http://www.tourister.ru/responses/id_10300 (дата обращения: 10.08.2019).

10. Варламов И. Нью-Йорк: хипстеры и красивый закат. URL: http://varlamov.ru/2056226.html (дата обращения: 10.08.2019).

11. Варламов И. Плохой Красноярск. 2016. Ч. 2. URL: http://varlamov.ru/1808973.html (дата обращения: 10.08.2019). 
12. Варламов И. Позор Красноярска 2016. URL: http://varlamov.ru/1804584.html (дата обращения: 10.08.2019).

13. Варламов И. Удивительный парк секвой. 2016. URL: http://varlamov.ru/1919648.html (дата обращения: 10.08.2019).

14. Варламов И. Хорн: тихая голландская идиллия. 2019. URL: https://varlamov.ru/3543526. html (дата обращения: 10.08.2019).

15. Гордеева О. Бросить все и уехать в Питер. 2016. URL: http://www.tourister.ru/responses/ id_17784 (дата обращения: 10.08.2019).

16. Гордеева О. Рязань как стиль жизни. 2017. URL: http://www.tourister.ru/responses/id_17926 (дата обращения: 10.08.2019).

17. Доля С. Алтай. Барнаул. 2013. URL: http://sergeydolya.livejournal.com/658447.html (дата обращения: 10.08.2019).

18. Доля С. Как насладиться золотом Черных гор. 2017. URL: http://sergeydolya.livejournal. com/1318527.html (дата обращения: 10.08.2019).

19. Доля С. Одесские улочки. 2013. URL: http://sergeydolya.livejournal.com/680970.html (дата обращения: 10.08.2019).

20. Доля С. Яркий Марракеш. 2015. URL: http://sergeydolya.livejournal.com/1143776.html (дата обращения: 10.08.2019).

21. Екатерина. Под небом Парижа. 2015. URL: http://www.tourister.ru/responses/id_12909 (дата обращения: 10.08.2019).

22. Екатерина. Самый «невьетнамский» город Вьетнама Далат. 2016. URL: http://www.tourister. ru/responses/id_17876 (дата обращения: 10.08.2019).

23. Елизавета. Хоп-хэй-лалалэй. Дрезден. 2016. URL: https://www.tourister.ru/responses/ id_16548 (дата обращения: 10.08.2019).

24. Лебедев А. Красноярск. 2008. URL: http://www.tema.ru/travel/ee-5/ (дата обращения: 10.08.2019).

25. Лебедев А. Лагос. 2012. URL: http://www.tema.ru/travel/lagos/ (дата обращения: 10.08.2019).

26. Левченко В. От берегов Альборана. Севилья. 2017. URL: http://vermut-777.tourister.ru/ photoalbum/30681 / (дата обращения: 10.08.2019).

27. Лискер Т. Дивногорье. Быль и небыль... 2016. URL: http:/www.tourister.ru/responses/ id_17158 / (дата обращения: 10.08.2019).

28. Лискер Т. Сингапур. Еще раз про любовь... 2016. URL: http://www.tourister.ru/responses/ id_17655 (дата обращения: 10.08.2019).

29. Петрова Д. Путешествие из Минска в Вильнюс. Кафе, латте и грейпфрут. 2015. URL: http:// venividi.ru/node/39118 (дата обращения: 10.08.2019).

30. Пилигрим. КрымТрип 3: Вдоль скалистых берегов. 2016. URL: http:/pilgrims-trip.ru/ krymtrip-3-vdol-skalistyx-beregov/ (дата обращения: 10.08.2019).

31. Пилигорим. На склонах Главного Кавказского хребта. 2013. URL: http:/pilgrims-trip.ru/nasklonax-glavnogo-kavkazskogo-xrebta/ (дата обращения: 10.08.2019).

32. Познер В. Для меня Сан-Франциско - сугубо американский город. 2016. URL: http:// pozneronline.ru/2016/09/16879/ (дата обращения: 10.08.2019).

33. Пушкарева В. Удивительные места Урала. Сунгуль и окрестности. URL: https://www. tourister.ru/responses/id_28252 (дата обращения: 10.08.2019).

34. Ренева Т. Горный Алтай: июньский водный. 2018. URL: https://www.tourister.ru/responses/ id_23789 (дата обращения: 10.08.2019).

35. Рубченкова А. Через всю Россию на Байкал. 2015. URL: http://www.tourister.ru/responses/ id_13713 (дата обращения: 10.08.2019).

36. Странник М. Рассвет в волшебном лесу. 2016. URL: http:/www.tourister.ru/responses/ id_17283 (дата обращения: 10.08.2019). 
37. Татьяна. По Европе с «музыкой»: день 7-й - Черногория. 2018. URL: https://vesnuschka2016. tourister.ru/photoalbum/36678 (дата обращения: 10.08.2019).

38. Юлия. Прага. Проникновение в сердце. 2019. URL: https://www.tourister.ru/responses/ id_27890 (дата обращения: 10.08.2019).

39. Dzeso. Звенигород. В ожидании весны. 2016. URL: http://dzeso.livejournal.com/695203. html\#cutid1 (дата обращения: 10.08.2019).

40. Shish_ka. Побег в Воронеж. 2016. URL: http://www.tourister.ru/responses/id_16724 (дата обращения: 10.08.2019).

41. Shish_ka. Башкирские просторы. 2015. URL: http://www.tourister.ru/responses/id_12991 (дата обращения: 10.08.2019).

\section{Библиографический список}

1. Басалаева Е.Г., Ружа О.А. Интернет-травелог: к вопросу о лингвистической интерпретации // Образы Италии в русской словесности. Томск, 2011. С. 560-572.

2. Гиндин С.И. Болевые точки теории речевых жанров // Русский язык сегодня: сб. докладов. М.: Флинта: Наука, 2015. Вып. 6. С. 55-61.

3. Кириллов А. Что такое травелог? // КРЯКК daily. № 1. 2015. 28 окт. С. 4.

4. Редькина Т.Ю. Этические и речевые нормы в трэвел-медиатексте // Экология языка и коммуникативная практика. 2014. № 1. С. 150-160.

5. Осетрова Е.В. О «речевой жизни» жанра: некоторые наблюдения и идеи // Коммуникация. Мышление. Личность. Саратов: Наука, 2012. С. 448-456.

\section{Сведения об авторе}

Богучарская Евгения Владимировна - аспирант, Красноярский государственный педагогический университет им. В.П. Астафьева; e-mail: evgenia. bogucharskaja@yandex.ru 
DOI: https://doi.org/10.25146/2587-7844-2019-8-4-27

\title{
SPEECH GENRE OF THE INTERNET TRAVELOGUE: THEMATIC FEATURES
}

\section{E.V. Bogucharskaya (Krasnoyarsk, Russia)}

\begin{abstract}
Travelogue is a popular speech genre in the Internet environment, the boundaries of which have not yet been established. The article discusses the thematic features of the Internet travelogue, which are one of its genre-forming features. The material for the study was the texts of unprofessional authors published on specialized tourist sites and in the Live Journal online diary. On the content level, the Internet travelogue as a speech genre is characterized by a wide range of topics and a variety of their expression. The definition of a combination of the topics described directly depends on the image of the author, who is interested in various aspects of travelling.

Keywords: speech genre, questionnaire of a speech genre, travelogue, Internet travelogue, theme; landscape, urban, philosophical, male, and female travelogues.

\section{Spisok istochnikov}

1. Andreeva K. Islandiya: tupikovyj put'. 2018. URL: https:/www.tourister.ru/world/europe/iceland/city/keflavik/placeofinterest/30029/responses/4207 (data obrashcheniya: 10.08.2019).

2. Belen'kij A. Kak zhivet amerikanskaya glubinka. 2016. URL: http://macos.livejournal. com/1392049.html (data obrashcheniya: 10.08.2019).

3. Belen'kij A. Kogda ochen' hochetsya v CHernogoriyu. 2016. URL: http://macos.livejournal. com/1440163.html (data obrashcheniya: 10.08.2019).

4. Belen'kij A. Staraya Zelandiya. 2016. URL: http://macos.livejournal.com/1443085.html (data obrashcheniya: 10.08.2019).

5. Belen'kij A. Uzbekistan. Zachet tuda voobshche ekhat'? 2018. URL: https://macos.livejournal. com/1739254.html (data obrashcheniya: 10.08.2019).

6. Belen'kij A. SHotlandiya. Pervye vpechatleniya. 2015. URL: http://macos.livejournal. com/1046958.html (data obrashcheniya: 10.08.2019).

7. Buyanova A. Bavariya i ya: Augsburg. 2016. URL: http://www.tourister.ru/responses/id_14456 (data obrashcheniya: 10.08.2019).

8. Buyanova D. Ot Londona radialochkoj. 2016. URL: http://www.tourister.ru/responses/id_17968 (data obrashcheniya: 10.08.2019).

9. Buyanova A. Skromnoe ocharovanie Rigi, ili kak polyubit' pirozhki s salom. 2014. URL: http:// www.tourister.ru/responses/id_10300 (data obrashcheniya: 10.08.2019).

10. Varlamov I. N'yu-Jork: hipstery i krasivyj zakat. URL: http://varlamov.ru/2056226.html (data obrashcheniya: 10.08.2019).

11. Varlamov I. Plohoj Krasnoyarsk. CHast' 2. 2016. URL: http://varlamov.ru/1808973.html (data obrashcheniya: 10.08.2019).

12. Varlamov I. Pozor Krasnoyarska 2016. URL: http://varlamov.ru/1804584.html (data obrashcheniya: 10.08.2019).

13. Varlamov I. Udivitel'nyj park sekvoj. 2016. URL: http://varlamov.ru/1919648.html (data obrashcheniya: 10.08.2019).

14. Varlamov I. Horn: tihaya gollandskaya idilliya. 2019. URL: https://varlamov.ru/3543526.html (data obrashcheniya: 10.08.2019).
\end{abstract}


15. Gordeeva O. Brosit' vse i uekhat' v Piter. 2016. URL: http://www.tourister.ru/responses/id_17784 (data obrashcheniya: 10.08.2019).

16. Gordeeva O. Ryazan' kak stil' zhizni. 2017. URL: http://www.tourister.ru/responses/id_17926 (data obrashcheniya: 10.08.2019).

17. Dolya S. Altaj. Barnaul. 2013. URL: http://sergeydolya.livejournal.com/658447.html (data obrashcheniya: 10.08.2019).

18. Dolya S. Kak nasladit'sya zolotom CHernyh gor. 2017. URL: http://sergeydolya.livejournal. com/1318527.html (data obrashcheniya: 10.08.2019).

19. Dolya S. Odesskie ulochki. 2013. URL: http://sergeydolya.livejournal.com/680970.html (data obrashcheniya: 10.08.2019).

20. Dolya S. YArkij Marrakesh. 2015. URL: http://sergeydolya.livejournal.com/1143776.html (data obrashcheniya: 10.08.2019).

21. Ekaterina. Pod nebom Parizha. 2015 URL: http://www.tourister.ru/responses/id_12909 (data obrashcheniya: 10.08.2019).

22. Ekaterina. Samyj «nev'etnamskij» gorod V'etnama Dalat. 2016. URL: http://www.tourister.ru/ responses/id_17876 (data obrashcheniya: 10.08.2019).

23. Elizaveta. Hop-hej-lalalej. Drezden. 2016. URL: https://www.tourister.ru/responses/id_16548 (data obrashcheniya: 10.08.2019).

24. Lebedev A. Krasnoyarsk. 2008. URL: http:/www.tema.ru/travel/ee-5/ (data obrashcheniya: 10.08.2019).

25. Lebedev A. Lagos. 2012. URL: http://www.tema.ru/travel/lagos/ (data obrashcheniya: 10.08.2019).

26. Levchenko V. Ot beregov Al'borana. Sevil'ya. 2017. URL: http://vermut-777.tourister.ru/photoalbum/30681 / (data obrashcheniya: 10.08.2019).

27. Lisker T. Divnogor'e. Byl' i nebyl'... 2016. URL: http://www.tourister.ru/responses/id_17158 / (data obrashcheniya: 10.08.2019).

28. Lisker T. Singapur. Eshche raz pro lyubov'... 2016. URL: http://www.tourister.ru/responses/ id_17655 (data obrashcheniya: 10.08.2019).

29. Petrova D. Puteshestvie iz Minska v Vil'nyus. Kafe, latte i grejpfrut. 2015. URL: http://venividi. ru/node/39118 (data obrashcheniya: 10.08.2019).

30. Piligrim. KrymTrip 3: Vdol' skalistyh beregov. 2016. URL: http://pilgrims-trip.ru/krymtrip-3vdol-skalistyx-beregov/ (data obrashcheniya: 10.08.2019).

31. Piligorim. Na sklonah Glavnogo Kavkazskogo hrebta. 2013. URL: http://pilgrims-trip.ru/nasklonax-glavnogo-kavkazskogo-xrebta/ (data obrashcheniya: 10.08.2019).

32. Pozner V. Dlya menya San-Francisko - sugubo amerikanskij gorod. 2016. URL: http://pozneronline.ru/2016/09/16879/ (data obrashcheniya: 10.08.2019).

33. Pushkareva V. Udivitel'nye mesta Urala. Sungul' i okrestnosti. URL: https://www.tourister.ru/ responses/id_28252 (data obrashcheniya: 10.08.2019).

34. Reneva T. Gornyj Altaj: iyun'skij vodnyj. 2018. URL: https://www.tourister.ru/responses/ id_23789 (data obrashcheniya: 10.08.2019).

35. Rubchenkova A. CHerez vsyu Rossiyu na Bajkal. 2015. URL: http://www.tourister.ru/responses/id_13713 (data obrashcheniya: 10.08.2019).

36. Strannik M. Rassvet v volshebnom lesu. 2016. URL: http://www.tourister.ru/responses/id_17283 (data obrashcheniya: 10.08.2019).

37. Tat'yana. Po Evrope s «muzykoj»: den' 7-j - CHernogoriya. 2018. URL: https://vesnuschka2016. tourister.ru/photoalbum/36678 (data obrashcheniya: 10.08.2019).

38. Yuliya. Praga. Proniknovenie v serdce. 2019. URL: https://www.tourister.ru/responses/id_27890 (data obrashcheniya: 10.08.2019).

39. Dzeso. Zvenigorod. V ozhidanii vesny. 2016. URL: http://dzeso.livejournal.com/695203. html\#cutid1 (data obrashcheniya: 10.08.2019). 
40. Shish_ka. Pobeg v Voronezh. 2016. URL: http://www.tourister.ru/responses/id_16724 (data obrashcheniya: 10.08.2019).

41. Shish_ka. Bashkirskie prostory. 2015. URL: http://www.tourister.ru/responses/id_12991 (data obrashcheniya: 10.08.2019).

\section{Bibliograficheskij spisok}

1. Basalaeva E.G., Ruzha O.A. Internet-travelog: k voprosu o lingvisticheskoj interpretacii [Internet travelogue: on the issue of linguistic interpretation] // ObrazyItalii v russkojslovesnosti [Images of Italy in Russian literature]. Tomsk, 2011. S. 560-572.

2. Gindin S.I. Bolevye tochki teorii rechevyh zhanrov [Pain points in the theory of speech genres] // Russkij yazyk segodnya: sb. dokladov [Russian language today]. M.: Flinta: Nauka, 2015. Vyp. 6. S. 55-61.

3. Kirillov A. CHto takoe travelog? [What is travelogue?] // KRYAKK, daily № 1. 2015. 28 okt. S. 4.

4. Red'kina T.Yu. Eticheskie i rechevye normy v trevel-mediatekste [Ethical and Speech Norms in Travel Media Text] // Ekologiya yazyka i kommunikativnaya praktika [Ecology of language and communicative practice]. 2014. № 1. S. $150-160$.

5. Osetrova E.V. O ,rechevoj zhizni” zhanra: nekotorye nablyudeniya i idei [On the ,speech life” of the genre: some observations and ideas] // Kommunikaciya. Myshlenie. Lichnost' [Communication. Thinking. Personality]. Saratov: Nauka, 2012. S. 448-456.

\section{About the author}

Bogucharskaya Evgeniya Vladimirovna - PhD Candidate of the Krasnoyarsk State Pedagogical University named after V.P. Astafiev; e-mail: evgenia.bogucharskaja@ yandex.ru 